\title{
Effect of Exercise and Obesity on Human Physiology
}

Irum Naureen ${ }^{1}$, Aisha Saleem ${ }^{2 *}$, Muhammad Naeem ${ }^{3}$, Noor-e-Maryam Bilal ${ }^{2}$, Ghulam Mujtaba Hassan², Muhammad Shafiq $^{2}$, Mudassar Hussain ${ }^{2}$, Syed Roohullah ${ }^{2}$

${ }^{1}$ Assistant Professor, School of Zoology, Minhaj University Lahore, Pakistan

${ }^{2}$ M. Phil Researcher, School of Zoology, Minhaj University Lahore, Pakistan

${ }^{3}$ Institute of Research and Information Mirpur AJK, Pakistan

DOI: $10.36348 /$ sb.2022.v08i01.003 $\quad$ | Received: 15.12.2021 | Accepted: 19.01.2022 | Published: 24.01 .2022

*Corresponding author: Aisha Saleem

M. Phil Researcher, School of Zoology, Minhaj University Lahore, Pakistan

\section{Abstract}

Physical activity and exercise on a regular basis can help you stay healthy, energetic, and independent as you age. Exercise is essential in preventing health problems such as heart disease and stroke. Many studies have demonstrated the health benefits of regular exercise. This report examines the evidence regarding the health benefits of exercise across the board. Physical activity and exercise can help to lower stress and anxiety, enhance happy neurotransmitters, promote selfconfidence, boost brain function, improve memory, and strengthen our muscles and bones. It also aids in the prevention and treatment of heart disease, obesity, blood sugar swings, cardiovascular disease, and cancer. It also aids in the prevention and treatment of heart disease, obesity, blood sugar swings, cardiovascular disease, and cancer. Regular physical activity has been shown the useful in the primary and secondary prevention of a variety of chronic diseases (e.g., cardiovascular disease, diabetes, cancer, hypertension, obesity, depression, and osteoporosis) as well as premature death.

Keywords: Obesity, exercise, blood sugar, body fat.

Copyright () 2022 The Author(s): This is an open-access article distributed under the terms of the Creative Commons Attribution 4.0 International License (CC BY-NC 4.0) which permits unrestricted use, distribution, and reproduction in any medium for non-commercial use provided the original author and source are credited.

\section{INTRODUCTION}

Physical activity is defined as any bodily movement that requires energy expenditure and is performed by skeletal muscles. "Physical activity" is not the same as "exercise." Exercise is a type of structured, repetitive, and intentional physical activity [1]". A healthy body equals a healthy mind." It means that if a person is weak, dull, or sick, he will be unable to complete his work effectively and efficiently."All parts of the body, if used in moderation and exercised in labours to which each is accustomed, become thereby healthy and well developed and age slowly," Hippocrates wrote in the 5th century BC, "but if they are unused and left idle, they become liable to disease, defective in growth, and age quickly"[2].

However, by the twenty-first century, belief in the value of exercise for health had waned to the point where a lack of exercise has become a major public health issue [2]. Similarly, a lack of exercise has been identified as a cause of chronic disease and death [3]. Exercise helps to decrease blood pressure and enhance circulation. Exercise aids in the loss of excess body weight, lowering blood pressure.
Calories are burned as a result of exercise. Exercise, when combined with good nutrition, is the most effective approach to avoid obesity. If a healthy individual does not exercise on a regular basis, he may become physically unfit. If we do not engage in regular physical activity, our muscles' efficiency decreases. As a result, we must engage in daily physical activity. Exercise has been linked to a variety of physical and physiological benefits that can help a person work more effectively and feel better. The articles given here are just a small sample of the over 100,000 studies that suggest a link between "exercise" and "health"[6].

\section{Exercise}

Exercise is a type of physical exercise that is organized, regulated, and repeated with the goal of conditioning a certain body area. Exercise is beneficial for improving health and fitness, as well as for physical rehabilitation. Exercise may also be defined as any bodily action that is done to improve or maintain physical fitness and general health. There are four types of exercise and physical activity. 1) Endurance, 2) strength, 3) Balance, 4) Flexibility [38]. 


\begin{tabular}{|l|l|}
\hline Endurance & $\begin{array}{l}\text { It raises your heart rate and breathing rate. They increase your overall fitness while keeping your } \\
\text { heart, lungs, and circulatory system healthy. Increasing your endurance makes it easier to complete } \\
\text { many of your daily tasks. This kind includes activities such as walking or running, mowing, raking, } \\
\text { digging, and dancing. }\end{array}$ \\
\hline Strength & $\begin{array}{l}\text { Muscles become stronger as a result of exercise. Even minor gains in strength can have a significant } \\
\text { impact on your ability. Lifting weights and utilizing a resistance band with your own body weight are } \\
\text { examples of this form of workout }\end{array}$ \\
\hline Balance & $\begin{array}{l}\text { Exercises can help prevent falls, which are a common problem among the elderly. Many lower-body } \\
\text { strength workouts will also help you gain balance. Many lower-body strength workouts will also help } \\
\text { you gain balance }\end{array}$ \\
\hline Flexibility & $\begin{array}{l}\text { Exercises assist your body stay limber by stretching your muscles. Being flexible allows you to move } \\
\text { more freely during other exercises and in everyday activities. Shoulder and upper arm stretch, calf } \\
\text { stretches, and yoga are some examples. }\end{array}$ \\
\hline
\end{tabular}

\section{Effect on the human body}

Physical exercises can be divided into two categories: aerobic and non-aerobic [4]. Aerobic exercise: It is any physical activity that requires the usage of big muscle groups and causes the body to consume more oxygen than when it is at rest. Aerobic exercise is intended to improve cardiovascular endurance [5, 39]. Cycling, swimming, brisk walking, skipping rope, rowing, hiking, tennis, continuous training, and long slow distance training are all examples of aerobic exercise. Anaerobic exercise: Strength and resistance training, which involves muscle firming, strengthening, and toning, as well as bone strength, balance, and coordination, can help to firm, strengthen, and tone muscles [6]. Push-ups, lunges, and dumbbell bicep curls are examples of strength exercises. Weight training, functional training, eccentric training, interval training, sprinting, and high-intensity interval training are all examples of anaerobic exercise that build short-term muscle strength [7].

\section{Exercise Is Crucial}

Muscles, blood, bones, and other living tissue make up each of our physical bodies. We become ill when any of these become harmed or stop performing properly. As a result, it is critical that we maintain a healthy and fit body. If we don't exercise, our muscles weaken and we become more stressed [18]. Getting enough sleep can help improve overall wellness and reduce stress. In terms of anxiety, the warm and hormones created during and after any physical activity can assist those who suffer from anxiety problems relax [8]. Getting some moderate-to-intense cardio on the track or treadmill Aerobic exercise of moderate to high intensity has been shown to lower anxiety sensitivity in certain people [9].

\section{Advantages}

\section{Impact on the lungs}

Regular exercise strengthens the heart and lungs, allowing the cardiovascular system to provide more oxygen to the body with each beating and the pulmonary system to enhance the maximum quantity of oxygen the lungs can absorb [10].

\section{The impact on body fat}

Exercise lowers blood pressure, lowers total and low-density lipoprotein (LDL) cholesterol (bad cholesterol) levels, and raises high-density lipoprotein (HDL) cholesterol levels (the good cholesterol). Heart attacks, strokes, and coronary artery disease are all reduced as a result of these beneficial impacts [11].

\section{Muscle and Joint Effects}

Exercise strengthens muscles, allowing people to perform tasks they might not be able to do otherwise or to do them more easily. Muscle strength and joint range of motion are required for every physical task. Both of these abilities can be improved with regular exercise [12]. Exercise stretches muscles and joints, increasing flexibility and reducing the risk of injury. Exercise can also assist to improve balance by strengthening the tissues around joints and throughout the body, reducing the risk of falling. Weight-bearing activity like brisk walking and weight training helps to strengthen bones and prevent osteoporosis [28].

Muscular-strengthening exercises can aid in the growth or maintenance of muscle mass and strength. By keeping joints in appropriate alignment, strong muscles and ligaments lessen the likelihood of joint and lower back pain. Additionally, changes to the circulatory and respiratory systems can promote greater oxygen and glucose delivery to the muscle during exercise [27]. People who engage in 120 to 300 minutes of moderate-intensity aerobic activity each week have a decreased risk of hip fracture [28], according to research.

\section{Effect on the levels of neurotransmitters and hormones}

Nor-epinephrine, a hormone that helps decrease the brain's response to stress, is also increased by exercise. Stress levels are considerably reduced when you are exercising. Physical activity that is both aerobic and anaerobic is beneficial to one's overall health. According to a study, 30 minutes of exercise five or more days a week helps to reduce despair and mental stress [10]. When it comes to anxiety, the warmth and hormones released during and after 
physical activity can help persons with anxiety disorders relax [8].

Exercise releases endorphins, which are happy and euphoric chemicals. Exercise has been demonstrated in studies to improve symptoms in clinically depressed people [11]. As a result, doctors advice that patients who are depressed or anxious do so. Exercise can be just as beneficial as antidepressant medications in treating depression in some situations.

\section{The impact on the brain cells}

Cardiovascular exercise has been proven in tests on mice and men to develop new brain cells (known as neurogenesis) and increase overall brain performance [12]. A rigorous workout has been shown to raise levels of a brain-derived protein (BDNF) in the body, which is thought to aid decision-making, higher thinking, and learning [8].

Physical activity improves memory and the ability to learn new things when done on a regular basis. Sweating stimulates the formation of memory and learning-related cells in the hippocampus [13]. As a result, studies have linked children's brain development to their level of physical fitness. However, exercisebased brainpower isn't just for kids; regular exercise can also help adults improve their memory. Running sprints increased language memory in healthy people, according to a research [14].

\section{The impact on the heart}

The heart is a muscle that requires regular exercise to stay in good form. Exercise helps to strengthen the heart muscles on a daily basis. When the heart is exercised, it can pump more blood through the body and continue to perform at peak efficiency with less effort. Regular exercise also helps to maintain the flexibility of arteries and other blood vessels, ensuring proper blood flow and blood pressure. Physical activity on a daily basis lowers the risk of heart disease [15].

\section{Effect on body mass index}

Excess calories are stored as fat in the body and an individual who consumes too many calories over time can become obese. Exercising can help you avoid gaining weight or keep it off once you've lost it. The higher the intensity of your physical activity, the more calories you will burn. Regular exercise (together with good nutrition) can help you lose weight. We will lose the most weight if we follow a cardiovascular exercise programme of moderate intensity activity for 5-7 days a week [16].

\section{Blood sugar levels are affected}

When it comes to diabetes management, exercise and diabetes go hand in hand. In T2D patients, a single bout of exercise increases glucose absorption by skeletal muscle, bypassing the insulin receptor and consequently insulin resistance $[17,20]$. Insulin triggers a sequence of modifications after attaching to its receptor, eventually boosting GLUT4 translocation to the plasma membrane [21, 22]. Insulin fails to promote GLUT4 translocation in T2D patients despite normal GLUT4 levels [23]. Exercise, on the other hand, aids GLUT4 expression translocation to the plasma membrane without requiring the insulin receptor. As a result, lower blood sugar levels. The impact of physical activity on blood glucose levels varies depending on how long you exercise and a variety of other factors. By making your body more responsive to insulin, physical activity can drop your blood glucose for up to 24 hours or more after your workout [24].

\section{Effect on cancerous cell}

Several basic studies have emerged on the relationship between cancer and brain activity [25]. The available literature indicates that this is due to a reduction in the incidence of certain cancers, especially colon and breast cancer, as a normal physical activity, as a poll or as a recreational activity [27]. Exercise can play a key role in further reducing the risk of many cancers. It has been estimated that 30 to 60 minutes of moderate psychological activity is required for areas with colon cancer, endometrial cancer and lung cancer. [28] Most studies show that more than 30 minutes of moderate-intensity activity is less likely than breast cancer, according to a new study [29].

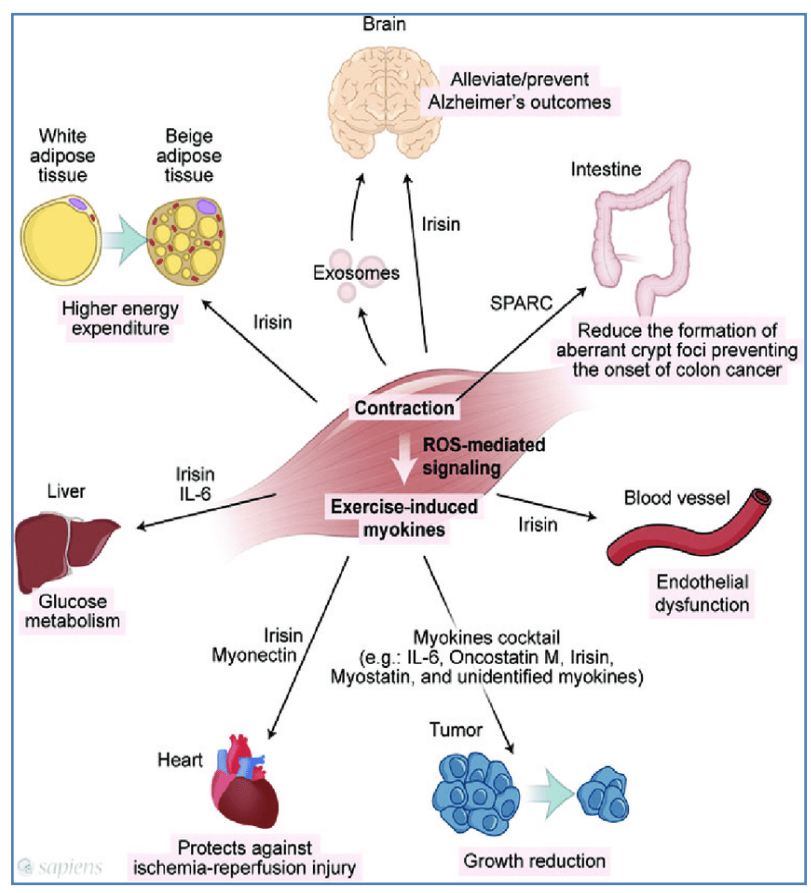

Fig-01: Tissue-specific metabolic effects of exercise [44] 
List of Physiological Disorder because of lack of exercise: [29]

\begin{tabular}{|c|c|}
\hline 1. Accelerated biological aging & 21. Hemostasis \\
\hline 2. Premature death & 22. Hypertension \\
\hline 3. Aerobic (cardiorespiratory) fitness & 23. Immunity \\
\hline 4. Arterial dyslipidemia & 24. Insulin resistance \\
\hline 5. Balance & 25. Metabolic syndrome \\
\hline 6. Bone fracture & 26. Nonalcoholic fatty liver disease \\
\hline 7. Breast cancer & 27. Obesity \\
\hline 8. Cognitive dysfunction & 28. Osteoarthritis \\
\hline 9. Colon cancer & 29. Osteoporosis \\
\hline 10. Congestive heart failure & 30. Ovarian cancer \\
\hline 11. Constipation & 31. Pain \\
\hline 12. Coronary (ischemic) heart disease & 32. Peripheral artery disease \\
\hline 13. Deep vein thrombosis & 33. Preeclampsia \\
\hline 14. Depression and anxiety & 34. Polycystic ovary syndrome \\
\hline 15. Diverticulitis & 35. Pre diabetes \\
\hline 16. Endometrial cancer & 36. Rheumatoid arthritis \\
\hline 17. Endothelial dysfunction & 37. Sarcopenia \\
\hline 18. Erectile dysfunction & 38. Stroke \\
\hline 19. Gallbladder diseases & 39. Tendons being less stiff \\
\hline 20. Gestational diabetes & 40. Type 2 diabetes \\
\hline
\end{tabular}

\section{Obesity}

It has been observed obesity is increasing day by day 30 years obesity is increasing a lot. However the more developed country is more there will be obesity life has become urbanize and modernize. It has been estimated that 300 million around the world have been exceeding from the BMI ratio. According to recent study USA population it has been expected that obesity will continue to increase by day.In Australia increasing is about $19 \%$ to $22 \%$ and females [43].

It is hard to know which factor is specifically responsible for obesity but, it is usually the food supply, eating behaviors, the new family work culture, lifestyle social and economical status more Urban Design live and public policies driving role in obesity [42]. It has been also observed that our genetics our genome from our parents could be also factor in obesity, the lifestyle, metabolic interaction in the body could also determining factor of obesity. A lot of factor has been changed from last 30 years; it is like a pandemic that everyone should have knowledge about, so that important preventive measure can be taken [42].

There is a lot of risk in obesity in health-wise disease, type 2 diabetes and hypertension disease that can be happen from obesity. So, those once have to take great care of psychological, emotional, nutritional and metabolic problems.

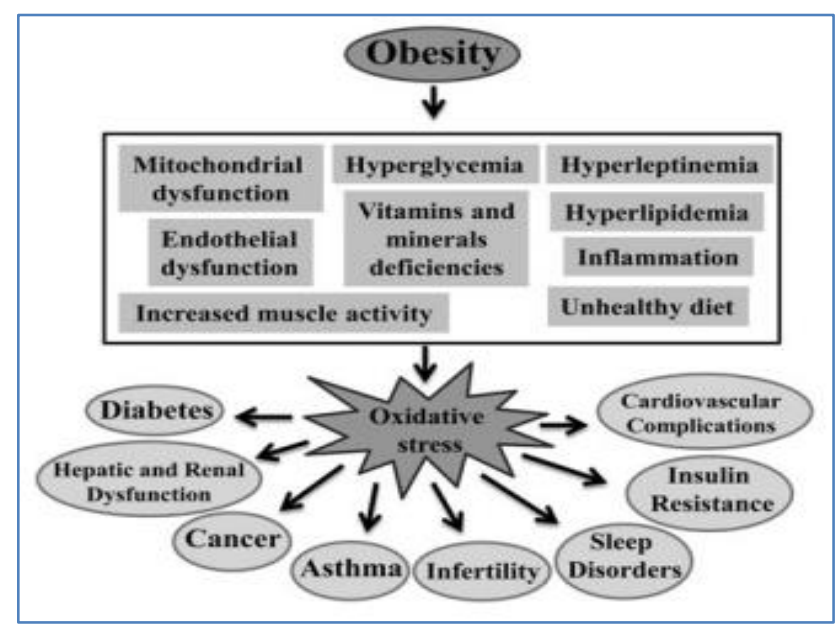

Fig-02: Obesity, oxidative stress, disinfection, associated tissue and health [43] 


\section{Effects of obesity on body}

Being overweight and obese are linked with great amount of risk for hypertension, diabetes abnormal cholesterol, coronary heart disease, stroke, disease related to gallbladder, sleep apnea, problem related to respiration and even cancer [31]. Obesity has severe health problems all around the world in all ages males and females, genetics is also responsible for obesity in person and it can be very from person to person, how to know if someone get obese the formula is simple it's taking high amount of calories than required in the body, and repeating this for days will get person obese.

\section{Effect of Obesity on heart}

Obesity also affects heart function, which increases the risk of heart failure. Increased cardiac output related to obesity, high blogger, metabolic regulation stress and, decreased fertility, included in epipardial fat, and myocardial fat infiltration are all obese-related cardiac eccentric and concentrated hair trophies [36]. Participate in a special farm. Framingham data show that I-obesity is twice as likely to be present in class III with cardiac [37].

\section{Obesity on blood pressure}

Increase level of circulating adhesion molecules, on the endothelial surface. E-selectin, pselectin and intracellular adhesion molecule-1. Endothelial contraindication is impaired with obesity, especially visceral obesity. Obesity is caused by arterial high blood pressure [32].

\section{Obesity induced oxidative stress}

Oxidative stress due to obesity leads to the development of various pathological events, including insulin resistance and diabetes, heart complications; sleep disorders, asthma, oncological problems, reproduction, arthritis problems, and liver failure. Growing evidence suggests that oxidative stress plays a key role in linking obesity to its associated complications. Obesity can cause systemic oxidative stress through various biochemical mechanismsSuch as NADPH oxidase to superoxide generation, oxidative phosphorylation, glyceraldehyde auto oxidation, protein kinase activation, and polyol and hexosamine pathways. Other factors that contribute to oxidative stress in obesity include hyperlipidemia, low antioxidant defenses, chronic inflammation, and post-pyramidal reactive oxygen species [31].

\section{Obesity induce inflammation}

Brown and white adipose tissues are two types of adipose tissue. White form of adipose tissue no longer taken as inert tissue, these tissues are considered as energy storage. It is promising as significant participant of pathological and physiological processes, inflammation and immunity included. Antiinflammatory plus pro-inflammatory factors like leptin, adipokines, resistin, chemokines, MCP-1, cytokines, IL6 , $\mathrm{TNF}-\alpha$, and adiponectin production depend on adipose tissue [40].

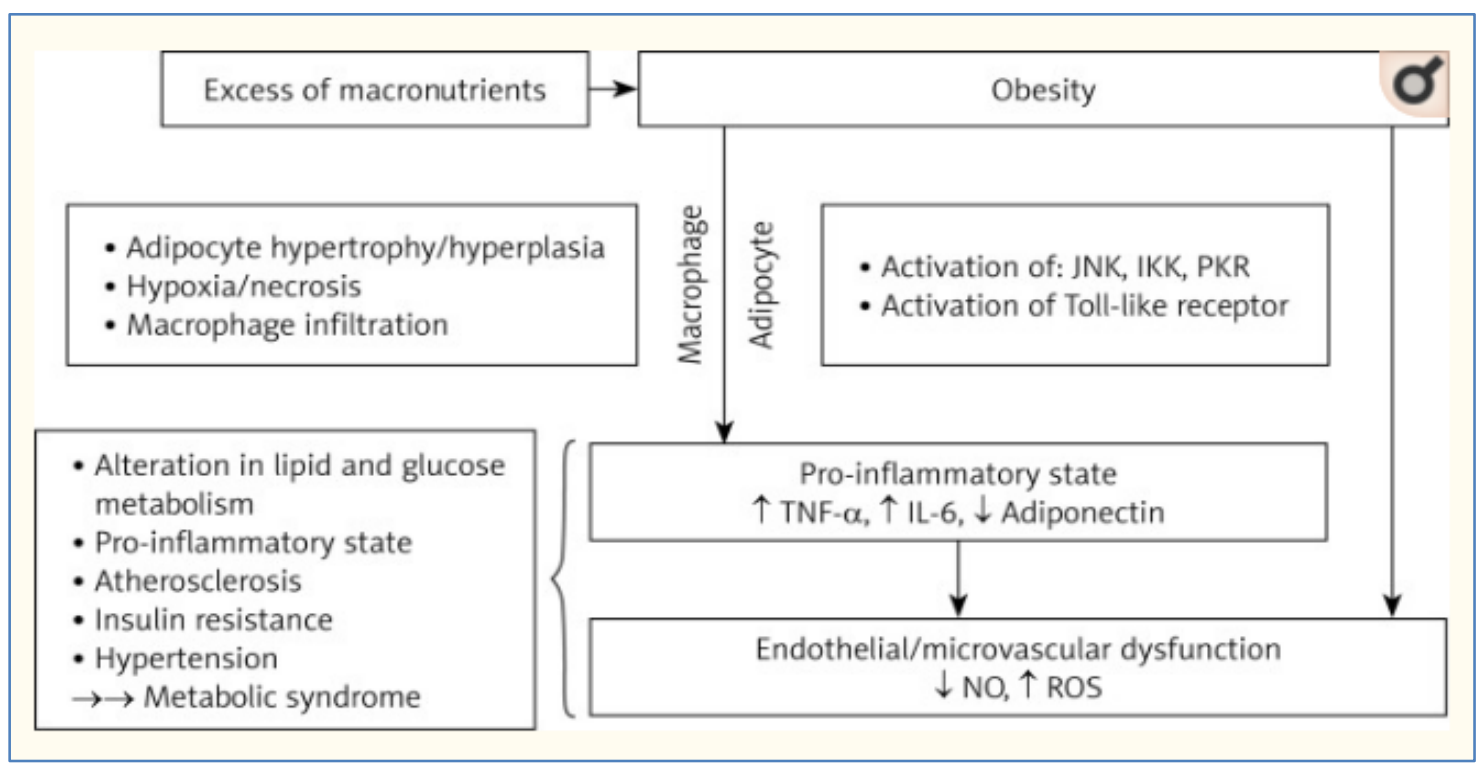

Fig-03: Excess of micronutrients and obesity reduce inflammation [40]

C-reactive protein synthesis from liver is stimulated by elevated level of interleukin- 6 . A reduced level of adiponectin, a significant predictor of cardiovascular mortality, is associated with impaired fasting glucose, leading to type-2 diabetes development, metabolic abnormalities, coronary artery calcification, and stroke [33].

Decrease in adiponectin leads to cardiovascular mortality, type-2 diabetes development 
because of impaired fasting glucose, stroke, metabolic abnormalities and calcification of coronary artery [33].

\section{Obesity effect on insulin}

Insulin resistance develop in obese person because of elevated level of glycerol, pro-inflammatory cytokines, hormones and increase production of non- esterified fatty acid (NEFA) by adipose tissue of obese individuals. Insulin resistance along with dysfunction of $\beta$-cell of pancreas which involve in insulin production leads to individual unable to control level of blood glucose. Hence risk of developing Diabetes type-2 depends on functional abnormalities of $\beta$-cell [34].

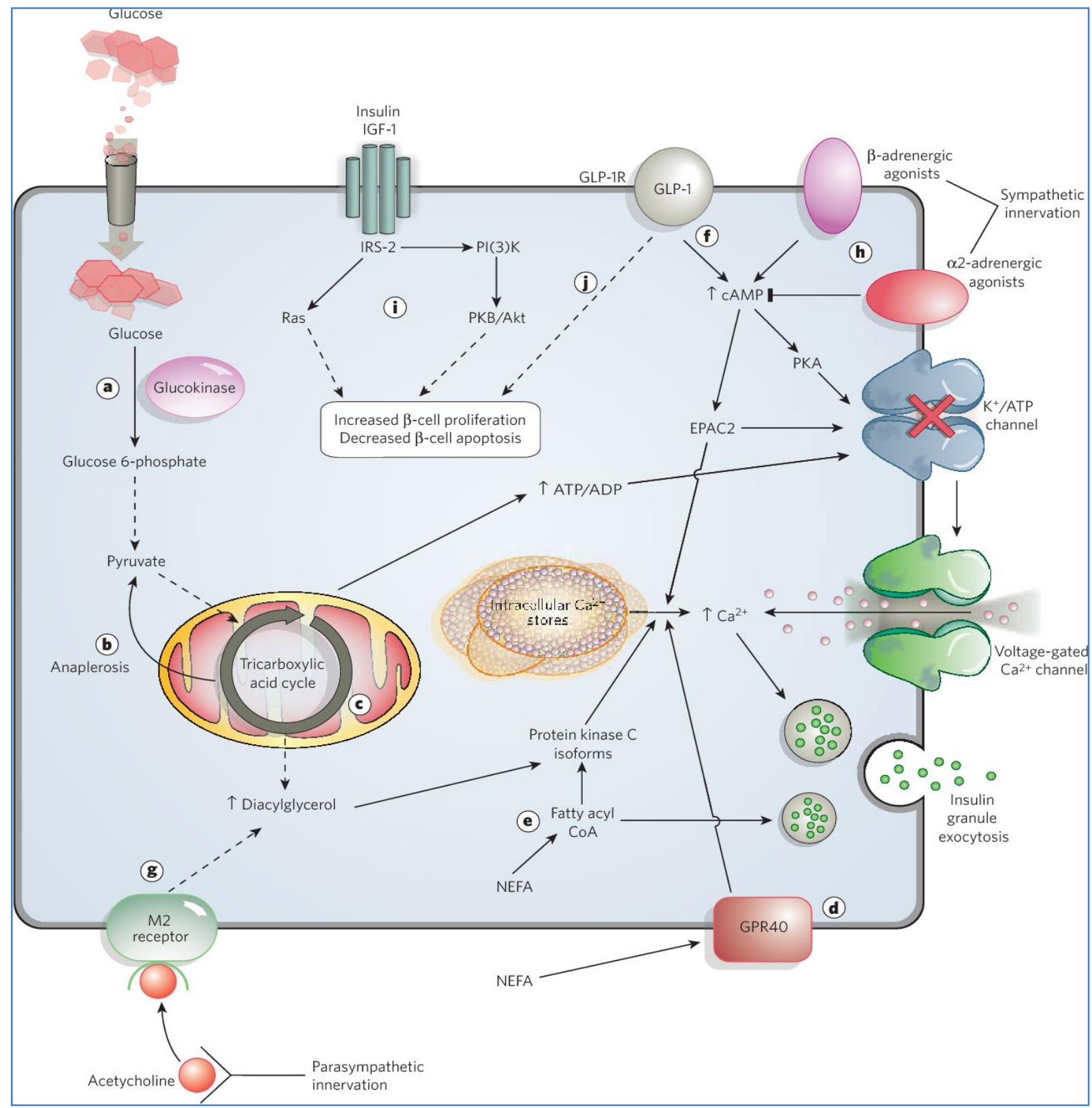

Fig-04: Simplified model outlining potential cellular mechanisms of $\beta$-cell adaptation to insulin resistance [40]

\section{CONCLUSION}

Weight loss is considered to be effective therapy for obesity and cormorbidity related to it. In prevention of obesity health care contributors, provider and researchers only play peripheral role while they have central role in effective treatment of diseases occurred in result of obesity. Overweight and obesity increases risk of osteoarthritis, hypertension, abnormal triglyceride and cholesterol level, heart diseases, stroke, diabetes type-2, sleep apnea, gallbladder, cancer and respiratory problems. Obesity is noteworthy health problem worldwide for group of all ages. Reason of obesity is consumption of more calories than number of calories burnt for long period. Genetic of person can involve in person becoming obese. Persons can manage their weight easily by doing exercise regularly. Several diseases, like cardiovascular disease, cancer and diabetes type-2 decreases with the exercise. Anxiety 
Irum Naureen et al., Sch Bull, Jan, 2022; 8(1): 17-24

and stress reduces with daily exercise. It also improves confidence level, increase mood lifting neurotransmitter, increase bone and muscle strength, sharpen memory, better brain power. Exercise gives both long term and immediate health benefits. Most importantly life quality improves with exercise. 30 min exercise per days increase chances of good and quality life.

\section{REFERENCE}

1. Organization, W.H. (2016). Physical activity strategy for the WHO European Region 2016-2025.

2. Booth, J. N., Bromley, L. E., Darukhanavala, A. P., Whitmore, H. R., Imperial, J. G., \& Penev, P. D. (2012). Reduced physical activity in adults at risk for type 2 diabetes who curtail their sleep. Obesity, 20(2), 278-284.

3. Brown, D. W., Brown, D. R., Heath, G. W., Balluz, L., Giles, W. H., Ford, E. S., \& Mokdad, A. H. (2004). Associations between physical activity dose and health-related quality of life. Medicine and science in sports and exercise, 36(5), 890-896.

4. Smith, S. C., Allen, J., Blair, S. N., Bonow, R. O., Brass, L. M., Fonarow, G. C., ... \& Taubert, K. A. (2006). AHA/ACC guidelines for secondary prevention for patients with coronary and other atherosclerotic vascular disease: 2006 update: endorsed by the National Heart, Lung, and Blood Institute. Journal of the American College of Cardiology, 47(10), 2130-2139.

5. Wilmore, J. H., \& Knuttgen, H. G. (2003). Aerobic exercise and endurance: improving fitness for health benefits. The Physician and sportsmedicine, 31(5), 45-51.

6. De Vos, N. J., Singh, N. A., Ross, D. A., Stavrinos, T. M., Orr, R., \& Fiatarone Singh, M. A. (2005). Optimal load for increasing muscle power during explosive resistance training in older adults. The Journals of Gerontology Series A: Biological Sciences and Medical Sciences, 60(5), 638-647.

7. Abou Elmagd, M. (2016). Benefits, need and importance of daily exercise. Int. J. Phys. Educ. Sports Health, 3(5), 22-27.

8. Griffin, É. W., Mullally, S., Foley, C., Warmington, S. A., O'Mara, S. M., \& Kelly, Á. M. (2011). Aerobic exercise improves hippocampal function and increases BDNF in the serum of young adult males. Physiology \& behavior, 104(5), 934-941.

9. Broman-Fulks, J. J., Berman, M. E., Rabian, B. A., \& Webster, M. J. (2004). Effects of aerobic exercise on anxiety sensitivity. Behaviour research and therapy, 42(2), 125-136.

10. Dunn, A. L., Trivedi, M. H., Kampert, J. B., Clark, C. G., \& Chambliss, H. O. (2005). Exercise treatment for depression: efficacy and dose response. American journal of preventive medicine, 28(1), 1-8.

11. Craft, L. L., \& Perna, F. M. (2004). The benefits of exercise for the clinically depressed. Primary care companion to the Journal of clinical psychiatry, 6(3), 104.

12. Mustroph, M. L., Chen, S., Desai, S. C., Cay, E. B., DeYoung, E. K., \& Rhodes, J. S. (2012). Aerobic exercise is the critical variable in an enriched environment that increases hippocampal neurogenesis and water maze learning in male C57BL/6J mice. Neuroscience, 219, 62-71.

13. Erickson, K. I., Voss, M. W., Prakash, R. S., Basak, C., Szabo, A., Chaddock, L., ... \& Kramer, A. F. (2011). Exercise training increases size of hippocampus and improves memory. Proceedings of the national academy of sciences, 108(7), 30173022.

14. Winter, B., Breitenstein, C., Mooren, F. C., Voelker, K., Fobker, M., Lechtermann, A., ... \& Knecht, S. (2007). High impact running improves learning. Neurobiology of learning and memory, 87(4), 597-609.

15. Fletcher, G. F., Balady, G., Blair, S. N., Blumenthal, J., Caspersen, C., Chaitman, B., ... \& Pollock, M. L. (1996). Statement on exercise: benefits and recommendations for physical activity programs for all Americans: a statement for health professionals by the Committee on Exercise and Cardiac Rehabilitation of the Council on Clinical Cardiology, American Heart Association. Circulation, 94(4), 857-862.

16. McBRIDE, T. R. A. V. I. S. (1998). Effect of weight training exercise and treadmill exercise on post-exercise oxygen consumption. Med Sci Sports Exerc, 30(4), 518-22.

17. Holloszy, J. O., \& Narahara, H. T. (1965). Studies of tissue permeability $\mathrm{X}$. Changes in permeability to 3-methylglucose associated with contraction of isolated frog muscle. Journal of Biological Chemistry, 240(9), 3493-3500.

18. Goodyear, L. J., \& Kahn, B. B. (1998). Exercise, glucose transport, and insulin sensitivity. Annual review of medicine, 49(1), 235-261.

19. Brüning, J. C., Michael, M. D., Winnay, J. N., Hayashi, T., Hörsch, D., Accili, D., ... \& Kahn, C. R. (1998). A muscle-specific insulin receptor knockout exhibits features of the metabolic syndrome of NIDDM without altering glucose tolerance. Molecular cell, 2(5), 559-569.

20. Holloszy, J. O. (2005). Exercise-induced increase in muscle insulin sensitivity. Journal of applied physiology, 99(1), 338-343.

21. Koeneman, M. A., Verheijden, M. W., Chinapaw, M. J., \& Hopman-Rock, M. (2011). Determinants of physical activity and exercise in healthy older adults: a systematic review. International Journal of Behavioral Nutrition and Physical Activity, 8(1), 1-15.

22. Stanford, K. I., \& Goodyear, L. J. (2014). Exercise and type 2 diabetes: molecular mechanisms regulating glucose uptake in skeletal 
muscle. Advances in physiology education, 38(4), 308-314.

23. Zierath, J. R., Krook, A., \& Wallberg-Henriksson, H. (2000). Insulin action and insulin resistance in human skeletal muscle. Diabetologia,43(7), 821835.

24. Ivy, J. L. (1997). Role of exercise training in the prevention and treatment of insulin resistance and non-insulin-dependent diabetes mellitus. Sports medicine, 24(5), 321-336.

25. Lee, I. M. (2003). Physical activity and cancer prevention--data from epidemiologic studies. Medicine and science in sports and exercise, 35(11), 1823-1827.

26. Shephard, R. J., \& Futcher, R. (1997). Physical activity and cancer: how may protection be maximized?. Critical Reviews $^{\mathrm{TM}}$ in Oncogenesis, 8(2-3).

27. Thune, I. N. G. E. R., \& Furberg, A. S. (2001). Physical activity and cancer risk: dose-response and cancer, all sites and site-specific. Medicine and science in sports and exercise, $33(6$ Suppl), S53050.

28. Kruk, J., \& Czerniak, U. (2013). Physical activity and its relation to cancer risk: updating the evidence. Asian Pacific Journal of Cancer Prevention, 14(7), 3993-4003.

29. Ruegsegger, G. N., \& Booth, F. W. (2018). Health benefits of exercise. Cold Spring Harbor perspectives in medicine, 8(7), a029694.

30. Warburton, D. E., Nicol, C. W., \& Bredin, S. S. (2006). Health benefits of physical activity: the evidence. Cmaj, 174(6), 801-809.

31. Dixon, J. B. (2010). The effect of obesity on health outcomes. Molecular and cellular endocrinology, 316(2), 104-108.

32. Re, R.N. (2009). Obesity-related hypertension. Ochsner Journal, 9(3); 133-136.

33. Manna, P., \& Jain, S. K. (2015). Obesity, oxidative stress, adipose tissue dysfunction, and the associated health risks: causes and therapeutic strategies. Metabolic syndrome and related disorders, 13(10), 423-444.

34. Kahn, S. E., Hull, R. L., \& Utzschneider, K. M. (2006). Mechanisms linking obesity to insulin resistance and type 2 diabetes. Nature, 444(7121), 840-846.

35. Kalantar-Zadeh, K., Block, G., Horwich, T., \& Fonarow, G. C. (2004). Reverse epidemiology of conventional cardiovascular risk factors in patients with chronic heart failure. Journal of the American College of Cardiology, 43(8), 1439-1444.

36. Zafrir, B., Salman, N., Crespo-Leiro, M. G., Anker, S. D., Coats, A. J., Ferrari, R., ... \& Heart Failure Long-Term Registry Investigators. (2016). Body surface area as a prognostic marker in chronic heart failure patients: results from the Heart Failure Registry of the Heart Failure Association of the European Society of Cardiology. European journal of heart failure, 18(7), 859-868.

37. Hubert, H. B., Feinleib, M., McNamara, P. M., \& Castelli, W. P. (1983). Obesity as an independent risk factor for cardiovascular disease: a 26-year follow-up of participants in the Framingham Heart Study. Circulation, 67(5), 968-977.

38. Bingham, S. A., Goldberg, G. R., Coward, W. A., Prentice, A. M., \& Cummings, J. H. (1989). The effect of exercise and improved physical fitness on basal metabolic rate. British Journal of Nutrition, 61(2), 155-173.

39. Epstein, L.H., \& Wing, R.R (1980). Aerobic exercise and weight. Addictive Behaviors 5, 371382.

40. Xu, H., Barnes, G. T., Yang, Q., Tan, G., Yang, D., Chou, C. J., ... \& Chen, H. (2003). Chronic inflammation in fat plays a crucial role in the development of obesity-related insulin resistance. The Journal of clinical investigation, 112(12), 1821-1830.

41. Jung, R. T. (1997). Obesity as a disease. Br.Med.Bull, 53: 307-321.

42. Fernández-Sánchez, A., Madrigal-Santillán, E., Bautista, M., Esquivel-Soto, J., Morales-González, Á., Esquivel-Chirino, C., ... \& Morales-González, J. A. (2011). Inflammation, oxidative stress, and obesity. International journal of molecular sciences, 12(5), 3117-3132.

43. Pollin, I. S., Kral, B. G., Shattuck, T., Sadler, M. D., Boyle, J. R., McKillop, L., ... \& Michos, E. D. (2008). High prevalence of cardiometabolic risk factors in women considered low risk by traditional risk assessment. Journal of Women's Health, 17(6), 947-953.

44. Zanuso, S., Jimenez, A., Pugliese, G., Corigliano, G., \& Balducci, S. (2010). Exercise for the management of type 2 diabetes: a review of the evidence. Acta diabetologica, 47(1), 15-22. 